\title{
Una inscripción de Senaquerib en la Real Academia de la Historia
}

\author{
Manuel MolinA
}

CSIC, Madrid

La renovación del Gabinete de Antigüedades de la Real Academia de la Historia (Madrid), que con tanta fortuna está impulsando Martín Almagro-Gorbea, ha propiciado que en fecha reciente me interesase por una inscripción cuneiforme que se conserva en sus fondos. Dicha inscripción pertenece al rey asirio Senaquerib (704-681 a.C.) y, como en ella misma se indica, procede de su palacio de Nínive (Kuyunjik, Iraq), ciudad a la que este monarca trasladó la capital del Imperio desde Dur-Sharrukin.

El texto de Senaquerib fue dado a conocer en 1895 por J. F. Riaño ${ }^{1}$, quien en una breve nota presentó la transcripción y la traducción que le había proporcionado A. H. Sayce. Aparentemente, Riaño no advirtió que de la inscripción de la RAH se había perdido el tercio derecho, y que, para disimular esa rotura, el tratante de antigüedades que la vendió trazó una incisión vertical que cerraba por la derecha el marco del texto ${ }^{2}$. De este modo, lo que Riaño tomó por la transcripción y traducción de todo el texto era, en realidad, una acertada reconstrucción que Sayce había hecho basándose en la conocida titulatura de Senaquerib.

\footnotetext{
${ }^{1}$ J. F. RIAÑo, «Inscripción asiria», Boletín de la Real Academia de la Historia 27 (1895) págs. 264-266.

2 Puede encontrarse una excelente fotografía de esta pieza en M. AlmagroGorbea (ed.), El Gabinete de Antigüedades de la Real Academia de la Historia (Madrid 1999) pág. 81 fig. 62, así como en el artículo de J. M. Peñuela citado en la nota siguiente.
} 
Años después, J. M. Peñuela ${ }^{3}$ reeditó en Sefarad esta misma inscripción. Tampoco este autor hizo mención alguna del estado de conservación de la pieza. Antes bien, Peñuela introdujo más confusión en el asunto al decir textualmente que «[en la obra de Meissner y Rost] encontramos justamente la reproducción o fiel copia de nuestra inscripción». Meissner y Rost, sin embargo, no reprodujeron en ninguna parte la inscripción de la RAH, sino un duplicado (este sí, con el texto completo) editado años atrás por Rawlinson ${ }^{4}$.

Aprovechando la publicación de nuevos detalles sobre la adquisición de la pieza de la RAH, así como la de recientes e importantes obras acerca de la epigrafía y las esculturas del palacio de Senaquerib, deseamos ofrecer en esta nota algunos datos más sobre el texto.

La inscripción fue adquirida, junto con otros dos bellos fragmentos de bajorrelieves del palacio de Senaquerib, por Antonio López de Córdoba. Con motivo de sus viajes al Próximo Oriente, este diplomático e historiador, importador de caballos de raza árabe, trabó probablemente amistad con A. H. Layard, arqueólogo de Nínive y Académico Honorario de la RAH desde 1870.

Conocedor de los importantísimos hallazgos que estaban teniendo lugar en Kuyunjik, López de Córdoba encargó las antigüedades a un famoso tratante de caballos, Nicolas Gliocho, quien al parecer las compró en Mosul en 1849. Sin embargo, Gliocho falleció en un viaje al Kurdistán, y tuvo que ser una comisión expresamente enviada a Oriente la que recuperara caballos y antigüedades. Estas llegaron a Madrid en noviembre de 1850 y fueron donadas a la Real Academia de la Historia en 1851 .

${ }^{3}$ J. M. Peñuela, «Tres restos de lápida asirios en la Real Academia de la Historia», Sefarad 26 (1966) págs. 247-252: págs. 249-250 + lám. I (fotografía).

${ }^{4}$ La transcripción y traducción de B. MEISSNER - P. ROST, Die Bauinschriften Sanheribs (Leipzig 1893) pág. 43 es la del texto publicado por H. RAWLiNSON, Cuneiform Inscriptions of Western Asia: I, A Selection from the Historical Inscriptions of Chaldaea, Assyria, and Babylonia (Londres 1861) pl. 6 no. 8A. La copia reproducida en el artículo de Peñuela es la publicada por B. MEISSNER - P. ROST, Die Bauinschriften Sanheribs, pl. 11: esta copia no es, desde luego, la del texto de la RAH, y aunque nada indican al respecto Meissner y Rost, probablemente corresponde al texto publicado por Rawlinson que ellos mismos transcriben y traducen en la pág. 43 de su libro.

${ }^{5}$ Almagro-Gorbea Gabinete pág. 33 y n. 40, quien en parte basa su información en el libro de A. K. STEEn, All the Queen's Horses. The Saga of Nicolas Gliocho's Life and Adventures, de próxima publicación. 
Puesto que es posible que bajorrelieves e inscripción fueran extraídos de la misma estancia, podría ser relevante determinar la ubicación concreta de las esculturas dentro del palacio.

En un libro de reciente publicación, Barnett, Bleibtreu y Turner ${ }^{6}$ han propuesto identificar los dos bajorrelieves como parte de la Sala IX del Palacio Suroeste de Senaquerib. Esta sala fue excavada por el equipo de Layard entre enero y marzo de $1850{ }^{7}$. El único testimonio que actualmente se conserva de sus bajorrelieves, y en el que se han basado los arqueólogos para realizar la mencionada identificación, lo constituyen unos dibujos realizados por $\mathrm{H}$. A. Churchill en Kuyunjik en 1851.

Hay, por tanto, algunas contradicciones entre las fechas de adquisición de las piezas y las de excavación y documentación gráfica de la sala a la que estas se asignarían. La explicación podría buscarse en la extracción de los bajorrelieves de la Sala IX antes de que esta fuese «oficialmente» excavada en 1850; sin embargo, también es posible que haya sido la azarosa vida de Gliocho la causa de estas «divergencias cronológicas» y que, en realidad, las piezas de la RAH no hubiesen sido adquiridas en 1849 , sino en 1850, poco después de la excavación de la Sala IX. En cualquier caso, los dibujos de Churchill de las esculturas de esa estancia del palacio casan perfectamente con los bajorrelieves de la RAH, y las diferencias de escala que observan los arqueólogos entre unas y otros muy bien pueden atribuirse a la escasa habilidad del dibujante ${ }^{8}$.

El texto de la inscripción es un duplicado exacto de otros que con frecuencia se colocaban en el reverso de algunos bajorrelieves, esculturas o losas del palacio o de fuera de él ${ }^{9}$. Este tipo de

${ }^{6}$ R. D. BARnetT - E. BleibTreu - G. TURner, Sculptures from the Southwest Palace of Sennacherib at Nineveh (Londres 1999) vol. I pág. 73; vol. II lám. 141 (núms. 205b-206b).

${ }^{7}$ J. M. RUSSELL, Sennacherib's Palace Without Rival at Nineveh (Chicago Londres 1991) pág. 36.

${ }^{8}$ BARNeTt - BleibTREU - TURner Sculptures vol. I págs. 16 y 73.

${ }^{9}$ Los duplicados del texto de la RAH pueden aparecer en los soportes que se indican a continuación. 1) En el reverso de relieves del Palacio Suroeste: RUSSELL Sennacherib's págs. 269-270 y fig. 132 (Sala I, Bloque 4); A. PATERsON, Assyrian Sculptures: Palace of Sinacherib (The Hague 1915) pág. 4 (Sala LI(n), Bloque 28); T. MADHLUM, «Nineveh, 1968-69 Campaign», Sumer 25 (1969) págs. 44-49: pág. 48 (Sala V). 2) En el reverso de los leones de la Sala I Puerta e: A. H. LAYARD, Inscriptions in the Cuneiform Character from Assyrian Monuments (Londres 1851) 
textos ha sido estudiado por E. Frahm («T. 71: Palastinschrift») ${ }^{10}$ y por J. M. Russell («The Texts on the Backs of Slabs») ${ }^{11}$.

A pesar de que en sus trabajos ninguno de estos dos autores ha tenido en cuenta el ejemplar de la RAH, también este pertenece a dicha clase de inscripciones. Según indica Russell, los textos de este tipo que se inscribían en el reverso de las esculturas o de los bajorrelieves se limitaban a ofrecer una breve indicación sobre el nombre y los títulos de Senaquerib, propietario del palacio. No estaban destinados, por tanto, a la lectura pública, por lo que podría pensarse que estaban dirigidos a los dioses o a reyes futuros y que servían para asociar el nombre del rey con su obra.

Los datos de catalogación de la inscripción son los siguientes:

- Núm. inv.: GA 1851/3.

- Medidas: altura, $32.5 \mathrm{~cm}$.; anchura, $59.5 \mathrm{~cm}$.; grosor, $5.5 \mathrm{~cm}$.

- Material: alabastro, también conocido como «mármol de Mosul» ${ }^{12}$.

- Procedencia: Palacio Suroeste de Senaquerib en la antigua Nínive (Kuyunjik, Iraq).

- Cronología: Senaquerib reinó entre los años 704 a 681 a.C. La construcción del palacio de Senaquerib puede datarse entre los años 703 a 691 a.C. ${ }^{13}$.

75:D. 3) En una losa de la «Procesión del Templo de Ishtar», entre el Palacio Suroeste y el Templo de Ishtar: C. J. GADD, The Stones of Assyria (Londres 1936) pág. 94. 4) En el reverso de una losa de Nebi Yunus: RawLinson Cuneiform pl. 6 no. 8A. Y 5) en otros fragmentos: R. C. THOMPSON - R. W. HAMILTON, «The British Museum excavations on the temple of Ishtar at Nineveh, 1930-31», Annals of Archaeology and Anthropology 19 (1932) págs. 55-116 + pl. XLVI-XCIV: pág. 114 núm. 261 pl. 81 , y núm. 262 pl. 81 = núm. 271 pl. 84; R. C. THOMPSON - R. W. HUTCHINSON, «The site of the palace of Ashurnasirpal at Nineveh, excavated in 1929-30 on behalf of the British Museum», Annals of Archaeology and Anthropology 18 (1931) págs. 79-112 + pl. XVII-XL: pág. 98 núm. 17 pl. 18. Estas referencias proceden de la bibliografía citada en las dos notas siguientes.

${ }^{10}$ E. FRAHM, Einleitung in die Sanherib-Inschriften, Archiv für Orientforschung Beiheft 26 (Viena 1997) pág. 140.

${ }^{11}$ J. M. RuSSELL, The Writing on the Wall: Studies in the Architectural Context of Late Assyrian Palace Inscriptions (Winona Lake 1999) págs. 127-128 y 211-212.

12 BARNETT - BleibTREU - TURNER Sculptures vol. I págs. 41-43.

${ }^{13}$ RUSSELl Sennacherib 's págs. 88-93. 
Transcripción

É.GAL md30-P[AP.MEŠ-SU]

MANGAL MAN kišs-[šá-ti]

MAN KUR aštšur dan-[dan-nu] e-til kal [mal-ki]

\section{Traducción}

Palacio de Senaquerib, el gran rey, el rey del mundo, el rey de Asiria, el poderoso, el señor de todos los reyes.

\section{RESUMEN}

La Real Academia de la Historia conserva en los fondos de su Gabinete de Antigüedades una inscripción del rey asirio Senaquerib (704-681 a.C.) procedente de su palacio de Nínive. Algunas inexactitudes en las ediciones del texto de J. F. Riaño (1895) y de J. M. Peñuela (1966), nuevas informaciones derivadas de los trabajos de catalogación del mencionado Gabinete de Antigüedades, así como la publicación de recientes e importantes obras acerca de la epigrafía y las esculturas del palacio de Senaquerib, aconsejaban revisar algunos aspectos de la inscripción. Esta fue probablemente extraída en torno a 1850 de la Sala IX del palacio, en concreto del reverso de alguno de los bajorrelieves o esculturas que adornaban dicha sala. Su texto no estaba destinado, por tanto, a la lectura pública: alude únicamente al palacio y a la titulatura de Senaquerib, y habría servido para asociar el nombre del rey a su monumental obra. Una pequeña parte de ella -dos hermosos bajorrelieves- se encuentran también depositados en la RAH y procedían quizá de la misma sala del palacio.

\section{SUMMARY}

Among the pieces of the Gabinete de Antigüedades of the Real Academia de la Historia we find one inscription of the Assyrian king Sennacherib (704-681 B.C.) which comes from his palace in Nineveh. Some innacuracies in the former editions of the text by J. F. Riaño (1895) and J. M. Peñuela (1966), new data emerged from the catalogue work of the pieces kept in the aforementioned Gabinete de Antigüedades, as well as the publication of recent and important works on the epigraphy and sculptures of Sennacherib's palace recommended the review of some aspects of the inscription. This was probably torne out from Room IX around 1850, in particular from the back of one of its relief slabs. The text was not accordingly intended for public reading. The cuneiform inscription mentions Sennacherib's palace and titles, possibly as a means of associating the name of the king with his monumental works. A small part of these, namely two beautiful reliefs, are also kept at the $\mathrm{RAH}$, and probably come from the same room of the Palace. 